\title{
Universal Power Law for Relationship between Rainfall Kinetic Energy and Rainfall Intensity
}

\author{
Seung Sook Shin, ${ }^{1}$ Sang Deog Park, ${ }^{2}$ and Byoung Koo Choi ${ }^{3}$ \\ ${ }^{1}$ Disaster Prevention Research Institute, Gangneung-Wonju National University, Gangneung 210-702, Republic of Korea \\ ${ }^{2}$ Department of Civil Engineering, Gangneung-Wonju National University, Gangneung 210-702, Republic of Korea \\ ${ }^{3}$ Department of Forest Environment Protection, Kangwon National University, Chuncheon 200-701, Republic of Korea
}

Correspondence should be addressed to Byoung Koo Choi; bkchoi@kangwon.ac.kr

Received 5 February 2015; Revised 24 May 2015; Accepted 28 May 2015

Academic Editor: Hongming He

Copyright (C) 2016 Seung Sook Shin et al. This is an open access article distributed under the Creative Commons Attribution License, which permits unrestricted use, distribution, and reproduction in any medium, provided the original work is properly cited.

\begin{abstract}
Rainfall kinetic energy has been linked to linear, exponential, logarithmic, and power-law functions using rainfall intensity as an independent variable. The power law is the most suitable mathematical expression used to relate rainfall kinetic energy and rainfall intensity. In evaluating the rainfall kinetic energy, the empirical power laws have shown a larger deviation than other functions. In this study, universal power law between rainfall kinetic energy and rainfall intensity was proposed based on the rainfall power theory under an ideal assumption that drop-size is uniformly distributed in constant rainfall intensity. An exponent of the proposed power law was 11/9 and coefficient was estimated at $10.3 \mathrm{from}$ the empirical equations of the existing power-law relation. The rainfall kinetic energy calculated by universal power law showed $>95 \%$ concordance rate in comparison to the average values calculated from exponential and logarithmic functions used in soil erosion model such as USLE, RUSLE, EUROSEM, and SEMMA and $<5 \%$ relative difference as compared to the average rainfall kinetic energies calculated by other empirical functions. Therefore, it is expected that power law of ideal assumption may be utilized as a universal power law in evaluating rainfall kinetic energy.
\end{abstract}

\section{Introduction}

Soil erosion is a natural process in all landform evolution and soil degradation along with various environmental problems. In water erosion, the impact of raindrop on the soil surface disperses soil aggregates. The rainfall kinetic energy is one of the useful indicators in the potential ability of rainfall for separating soil particles from the soil surface. Basically, the rainfall kinetic energy results from the kinetic energy of individual raindrops that strikes the soil. The calculation of the rainfall kinetic energy requires drop-size, drop-velocity, and drop-volume measurements as well as drop-size distribution (DSD). DSD data has been obtained using various techniques such as filter paper, flour pellet, camera, optical array, and meteorological radar [1-7]. The rainfall kinetic energy can be calculated by the measured DSD combined with empirical $V_{t}(D)$ laws [8-10], direct measurement using a pressure transducer or acoustic devices
$[11,12]$ or using an Optical Spector Pluviometer allowing the real time measurement of drop-size and drop-velocity [7]. Many empirical equations of the rainfall kinetic energy $\left(E_{k}\right)$ linked to the easily available rainfall intensity $(I)$ are proposed on the basis of drop-size and drop-velocity measurements. The empirical equations for the rainfall kinetic energy in various mathematical expressions have been developed in the form of power-law, exponential, logarithmic, and linear functions.

In the empirical soil erosion models, the rainfall kinetic energy has been used as erosivity factor of splash erosion, sheet erosion, and rill erosion modeling [13-16]. USLE [13], soil erosion models based on agricultural area in the United States, used a logarithmic function of rainfall kinetic energy developed by Wischmeier and Smith [13], and RUSLE [14] used an exponential function proposed by Brown and Foster [17]. Under the assumption based on the DSD measurements [18], EUROSEM [15], the representative soil erosion model 
in Europe, used a logarithmic function presented by Brandt [19]. SEMMA [16] developed in South Korea adopted an exponential function of Van Dijk et al. [20]. However, they require the validation in a wide range of environmental settings since these functions were focused on restricted areas with different environmental settings and measurement technique.

There are no distinct criteria on what is the most suitable function as rainfall erosivity factor of the soil erosion. Many researchers suggested that the maximum value of the rainfall kinetic energy exists in the natural rainfall events $[3,17$, 21-24]. The exponential function which converges to the limited value was judged to be function that better describes the relationship between rainfall kinetic energy and rainfall intensity $[3,25]$ because there is no upper limit in the powerlaw, logarithmic, and linear functions. Van Dijk et al. [20] proposed a general equation of the exponential type from the measured data through a literature review on the relationship between rainfall kinetic energy and rainfall intensity. The empirical power-law relation from the observation of rainfall intensity and radar reflectivity factors using a statistical model of the DSD was presented by Smith and de Veaux [26]. In particular, Salles et al. [27] proved that the timespecific kinetic energy is the most appropriate expression of the empirical law between rainfall kinetic energy and rainfall intensity in the statistical and physical basis and presented that the power law between rainfall kinetic energy and rainfall intensity is the most suitable mathematical function as considering the DSD models.

The existing empirical equations between rainfall kinetic energy and rainfall intensity showed significantly different coefficients according to geographical location and measurement technique. Therefore, it is not easy to apply in other countries or regions having different types of rainfall $[4,20$, 28]. In particular, power law in calculation of rainfall kinetic energy shows larger deviation compared to exponential and logarithmic functions $[26,29]$. There were few cases that the power law had been used as rainfall erosivity index in developed soil erosion models although it is simple and suitable mathematical expression. Therefore, it is necessary to present the representative power law obtained from various rainfall kinetic energy equations. This study attempts to propose a new equation of power law based on the rainfall power theory under the ideal assumption that drop-size is uniformly distributed in constant rainfall intensity. In addition, our newly proposed power law is evaluated through comparing with existing empirical equations.

\section{Theory}

2.1. Relationship between Rainfall Kinetic Energy and Rainfall Intensity. In general, the relationships between rainfall kinetic energy and rainfall intensity are presented in the form of exponential [4, 17, 24, 28, 30-34], logarithmic [3, 13, 28, 3437], linear [24, 28, 38-40], and power-law [26, 28, 29, 33, 41, 42] functions.

The rainfall kinetic energy can be expressed in two ways of volume-specific and time-specific kinetic energy. The volume-specific kinetic energy is expressed as the amount of rainfall kinetic energy expended per unit volume of rain $[13,20,36,43]$ while time-specific kinetic energy is the rate of expenditure of rainfall kinetic energy or rainfall power and expressed as rainfall kinetic energy expended per unit area and per unit time $[3,26,29]$. In the relationship between rainfall kinetic energy and rainfall intensity, the two expressions of volume-specific rainfall kinetic energy $E_{k-\mathrm{mm}}\left(\mathrm{J} / \mathrm{m}^{2} / \mathrm{mm}\right)$ and time-specific rainfall kinetic energy $E_{k \text {-time }}\left(\mathrm{J} / \mathrm{m}^{2} / \mathrm{h}\right)$ are related to each other through the rainfall intensity as shown in the following:

$$
E_{k \text {-time }}=I E_{k-\mathrm{mm}} \text {. }
$$

As reported by Sempere-Torres et al. [39], the scatterplots of $E_{k \text {-time }}-I$ have less heteroscedasticity than those of $E_{k-\mathrm{mm}}-I$, and $E_{k-\mathrm{mm}}$ is more sensitive to the DSD of rainfall [27] so that the connection of $E_{k \text {-time }}$ with $I$ is more suitable compared to $E_{k-\mathrm{mm}}$. Therefore, this study investigates the relationship between time-specific rainfall kinetic energy (hereafter, $E_{k}$ ) and rainfall intensity.

Exponential, logarithmic, linear, and power-law functions of time-specific rainfall kinetic energy can be expressed as general equations using empirical coefficients of $a, b$, and $c$ as shown in the following equations:

$$
\begin{aligned}
& E_{k}=a I\left(1-b \mathrm{e}^{-c I}\right), \\
& E_{k}=I(a+b \log I), \\
& E_{k}=a(I-b), \\
& E_{k}=a I^{b} .
\end{aligned}
$$

Reported empirical relationships between rainfall kinetic energy and rainfall intensity are summarized in Table 1. In case of exponential function developed widely, only reliable functions organized by Salles et al. [27] and Van Dijk et al. [20] were reported as considering the range of rainfall intensity and the number of observations and determination coefficient of measured data. Also, the linear and logarithmic function include the reliable empirical equations along with equations organized by Salles et al. [27]. Representative forms of the power law include six typical power laws presented using DSD data from the Illinois State Water Survey of the Unites States [26] and six different sets on power law between rainfall related variables and rainfall intensity were presented based on different assumptions regarding the rainfall intensity dependence of the DSD parameters [29]. With continuous and direct drop-size and drop-velocity measurements, kinetic energy equations recently developed in the Republic of Korea were organized in Table 1 [33, 34, 42].

2.2. Review of Mathematical Power Laws. Many researchers demonstrated that a power law is the most suitable mathematical function between rainfall kinetic energy and rainfall intensity [27, 44]. Therefore, the power law presented by Salles et al. [27] is summarized in these passages to understand a mathematically rational power law used to link $I$ with $E_{k}$. 


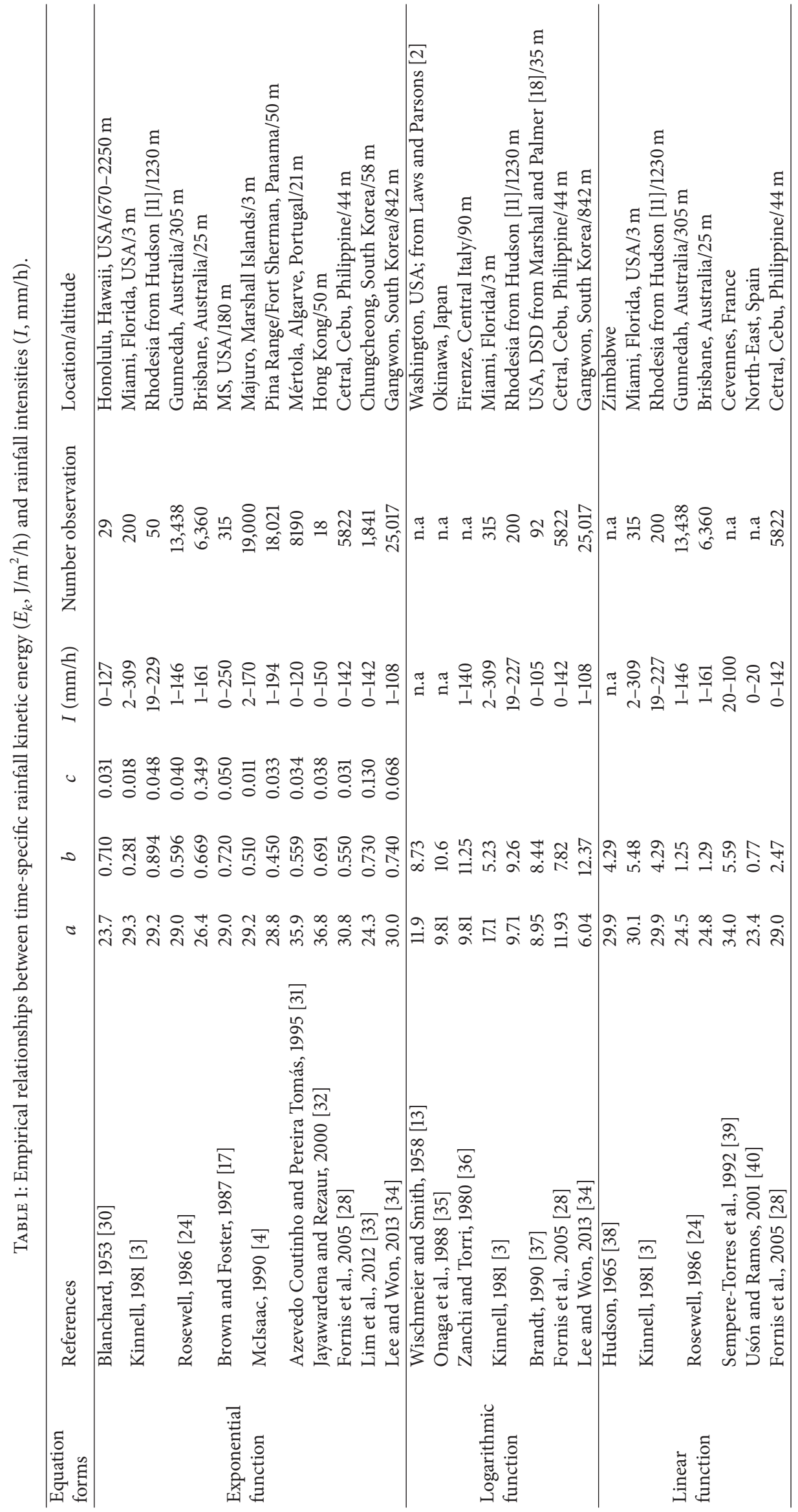




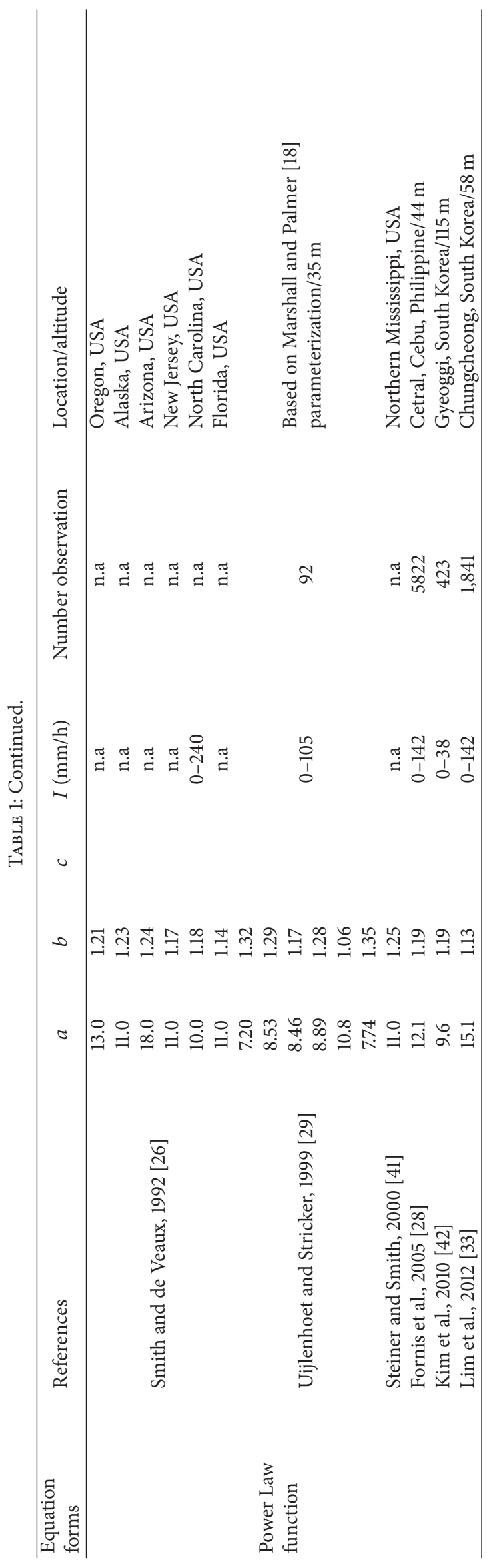


The time-specific rainfall kinetic energy $E_{k}\left(\mathrm{~J} / \mathrm{m}^{2} / \mathrm{h}\right)$, the rainfall kinetic energy flux density $[41,45]$, is calculated by the DSD and drop-velocity measurement data:

$$
E_{k}=3.6 \times 10^{-3} \frac{\rho \pi}{12} \sum_{i} X\left(D_{i}\right) D_{i}^{3} V_{t}^{2}\left(D_{i}\right),
$$

where $\rho$ is the water density $\left(\mathrm{kg} / \mathrm{m}^{3}\right)$ in standard conditions, $D_{i}$ is a diameter of raindrop $(\mathrm{cm}), X\left(D_{i}\right)$ is the number of drops with diameter $D_{i}$ arriving per unit time and per unit area, and $V_{t}(D)$ is the terminal fall velocity of a raindrop with diameter $D_{i}$.

Rainfall intensity $I(\mathrm{~mm} / \mathrm{h})$ is derived from the droplet flux density:

$$
I=3.6 \frac{\pi}{6} \sum_{i} X\left(D_{i}\right) D_{i}^{3}
$$

Sempere-Torres et al. [44, 46] mentioned the various mathematical expressions of the DSD described by exponential, gamma, lognormal, or Weibull distribution functions $[18,47-49]$ and presented that all DSD models follow the power law as the most appropriate relationship between $E_{k}$ and $I$. The general formulation of the DSD using $I$ as reference variable is expressed as follows:

$$
N(D, I)=I^{\alpha} g\left(D I^{-\beta}\right) .
$$

The general formulation of an analytical relation between $E_{k}$ and $I$ is expressed by raindrop flux density replacing DSD and the terminal fall velocity:

$$
E_{k}=3.6 \times 10^{3} \frac{\rho \pi}{12} I^{\alpha} \int_{D_{\min }}^{D_{\max }} g\left(D I^{-\beta}\right) D^{3} V_{t}^{2}(D) d D
$$

Using a terminal fall velocity $V_{t}(D)=a_{0} D^{b_{0}}$ and the variable $x=D I^{-\beta}(9)$ becomes

$$
E_{k}=3.6 \times 10^{3} \frac{\rho \pi}{12} I^{\alpha+\beta\left(4+3 b_{0}\right)} \int_{x_{\min }}^{x_{\max }} g(x) x^{3\left(b_{0}+1\right)} d x .
$$

The remaining terms except $I$ are defined as $A$ being a constant. If $V_{t}(D)$ proposed by Atlas and Ulbrich [50] is used, $A$ and $E_{k}$ can be expressed simply as follows:

$$
E_{k}=A I^{1+1.34 \beta} \text {. }
$$

The exponent of the relation between $E_{k}$ and $I$ depends on only one variable $\beta$. In various climate conditions, the coefficient $A$ is well expressed by gamma distribution with a single free variable $\mu$ presented by Sempere-Torres et al. [46] or Salles et al. [51]. Therefore, the coefficient $A$ is simply expressed below:

$$
A=1288.17 \mu^{-1.34}
$$

Finally, the power law of $E_{k}\left(\mathrm{~J} / \mathrm{m}^{2} / \mathrm{h}\right)$ presented by Salles et al. [27] is described as follows:

$$
E_{k}=1288.17 \mu^{-1.34} I^{1+1.34 \beta} .
$$

In the presented $E_{k}-I$ relationship, the parameters $\mu$ and $\beta$ are linked to the type of microphysical process related to the growth of raindrops [27]. In the previously reported studies, $\mu$ is applicable to the range between 30 and 40 . Typical values around 30 are related to convective rainfall $[44,46,51]$ and the values $\mu=40$ and $\mu=50$ are commonly associated with stratified rainfall [18] and drizzle [52], respectively. Regarding the parameter $\beta$, Marshall and Palmer [18] reported values around 0.12 to 0.15 are suitable to convection rainfall and the value $\beta=0.21$ is related to a wide range of stratified rainfall. In the general form of given power law in (5), the coefficient and exponent are transformed into mathematical power functions of Salles et al. [27] as shown below:

$$
\begin{aligned}
& a=1288.17 \mu^{-1.34}, \\
& b=1+1.34 \beta .
\end{aligned}
$$

The coefficient $a$ of the power law is 13.5 for convective rainfall and 9.2 for the wide range of stratified rainfall. The exponent $b$ varies from 1.0 to 1.4 , and the values around 1 are suitable for strong rainfall.

\section{Establishment of Ideal Equation for Rainfall Power}

Despite the definition of the functional relationship between rainfall kinetic energy and rainfall intensity, exponents and coefficients of the power law are largely different depending on parameters such as rainfall type, geographical location, and measurement techniques. Therefore, a general equation which represents empirical power law is required to evaluate soil erosion in the area where there is no measurement data of rainfall kinetic energy. The power of raindrop falling on the surface soil is derived theoretically under the ideal assumption that the diameter of raindrop is uniform for constant rainfall intensity. This assumption is based on the judgment that the error caused by this ideal assumption would be smaller than the difference in rainfall kinetic energies estimated by various types of empirical power law $[26,29]$.

The power of raindrop particles striking on the surface soil is defined by the multiplication of the force and terminal velocity of freefalling raindrop:

$$
P_{R}=\sum F_{R} V_{t}(D)
$$

where rainfall power $P_{R}$ is the expended energy per unit area and per time $\left(\mathrm{J} / \mathrm{m}^{2} / \mathrm{s}\right)$, the force of rainfall $F_{R}$ is the water weight per unit area $\left(\mathrm{N} / \mathrm{m}^{2}\right)$, and $V_{t}(D)$ is the terminal velocity of raindrop $(\mathrm{m} / \mathrm{s})$.

Atlas and Ulbrich [50] have suggested the power law based on the terminal velocity data presented by Gunn and Kinzer [9]; the terminal fall velocity is proportional to the diameter of raindrop:

$$
V_{t}(D)=17.67 D^{0.67},
$$

where $D$ is mean diameter $(\mathrm{cm})$ of uniform raindrop. 
A freefalling raindrop is affected by gravity and the resistance force. The velocity of a falling raindrop keeps the steady condition when two forces are equal. The terminal fall velocity can be expressed as reported by Zhou et al. [53]:

$$
V_{t}(D)=\left(\frac{D^{2} \rho g}{6 K}\right)^{1 / 3},
$$

where $g$ is the acceleration by gravity $\left(\mathrm{m} / \mathrm{s}^{2}\right)$ and $K$ is the constant in the certain range of raindrop diameter $\left(\mathrm{kg} \mathrm{s} / \mathrm{m}^{3}\right)$. Therefore, the relationship of the terminal velocity and raindrop diameter is expressed as $V_{t}(D) \propto D^{2 / 3}$.

If the raindrop flux density $X(D)$ is the number of raindrops with a uniform diameter $D$ per unit area and per unit time, rainfall intensity equation can be expressed simply as follows:

$$
I=\frac{\pi}{0.6} X(D) D^{3} .
$$

The above equation is expressed into the equation of uniform diameter of raindrop as follows:

$$
D=\left[\frac{I}{0.6 \pi X(D)}\right]^{1 / 3} .
$$

The uniform diameter in (19) is substituted in the terminal velocity of (16) and it is then substituted in rainfall power equation as follows:

$$
P_{R}=17.67\left[\frac{I}{0.6 \pi X(D)}\right]^{2 / 9} \sum F_{R} .
$$

Since the weight of rainfall per unit area is the product of the specific weight and rainfall amount, it is derived from

$$
\sum F_{R}=10^{-3} \gamma_{w} R,
$$

where $\gamma_{w}$ is the unit weight of raindrop water $\left(\mathrm{N} / \mathrm{m}^{3}\right)$ and the amount of rainfall $R(\mathrm{~mm})$ has relationship of $R=I \cdot t$ with rainfall intensity.

When the weight of rainfall in (21) is substituted in the rainfall power equation, it is expressed as in the following:

$$
P_{R}=\frac{150 t}{X(D)^{2 / 9}} I^{11 / 9} .
$$

If the equation of rainfall power per unit area $\left(\mathrm{J} / \mathrm{m}^{2} / \mathrm{s}\right)$ is converted to the equation of time-specific rainfall kinetic energy $\left(\mathrm{J} / \mathrm{m}^{2} / \mathrm{h}\right)$, and time $t$ is 1 hour, the ideal equation of rainfall power is derived as follows:

$$
E_{k}=\frac{150}{X(D)^{2 / 9}} I^{11 / 9} .
$$

Therefore, time-specific rainfall kinetic energy $\left(E_{k}\right)$ from rainfall power theory is proportional to $11 / 9$ power of rainfall intensity $I$ and is in inverse proportion to $2 / 9$ power of the number of raindrops, $X(D)$.

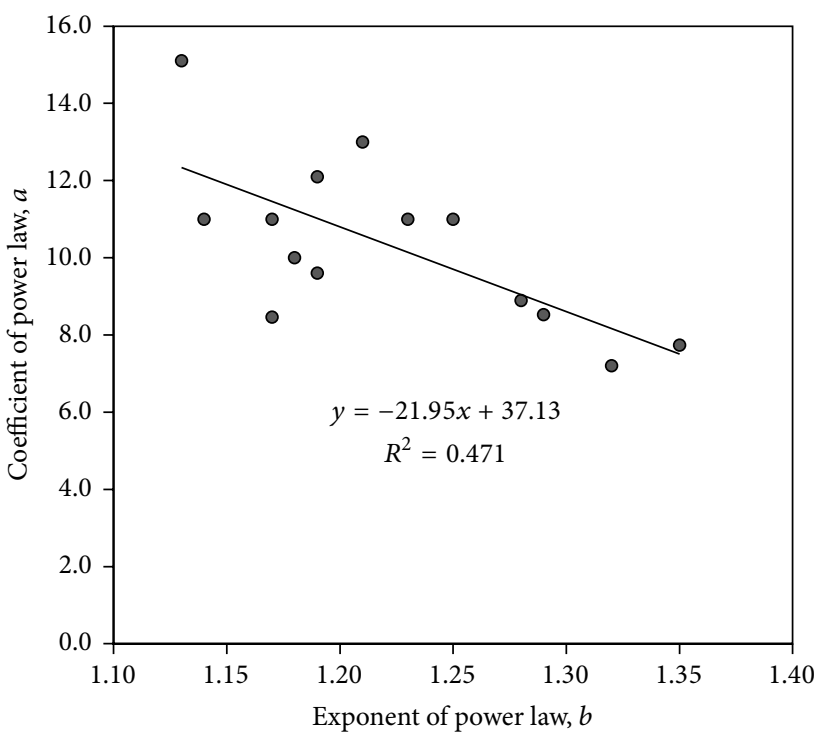

FIGURE 1: Relationship between coefficients and exponents of empirical power laws.

The exponent 11/9 of rainfall power function was theoretically derived from ideal assumption that the drop-size is uniform in constant $I$. The coefficient can be calculated if the number of raindrops is identified. DSD to describe a population of falling drops obviously depends on the diameter and $I$ [44] influenced by location, climate, and rainfall type [44]. Therefore, the coefficient can be obtained from the power laws developed based on empirically available DSD expressed by many researchers. In Table 1 , the maximum $(a=18.0$, $b=1.24)$ and minimum $(a=10.8, b=1.06)$ kinetic energy equations which show $>30 \%$ difference from the calculated rainfall kinetic energies are excluded from regression analysis of empirical power laws. The linear regression equation $(r=$ $0.686, p=0.0068$ ) from reliable power law is shown as in Figure 1 . The coefficient $a$ was 10.3 when the exponent $(b=11 / 9)$ for ideal power law was substituted in the linear regression equation $(a=-21.95 b+37.13)$. Thus, the power law of time-specific rainfall kinetic energy by ideal assumption is proposed as follows:

$$
E_{k}=10.3 I^{11 / 9} .
$$

\section{Evaluations and Discussions}

We compared the relationship between existing empirical equations and the ideal equation of rainfall power to evaluate the availability as the universal power law.

The average value of rainfall energies calculated by 13 exponential functions $[4,17,24,28,30-34]$ presented in Table 1 was fitted with the result simulated by the ideal power law of rainfall power $(a=10.3, b=11 / 9)$ in Figure 2(a). The rainfall energy calculated by the ideal power law was distributed within the range of standard deviation of exponential functions. In case of rainfall intensity $<80 \mathrm{~mm} / \mathrm{h}$, the average value by exponential functions was greater than that of ideal power law while ideal power law had relatively 


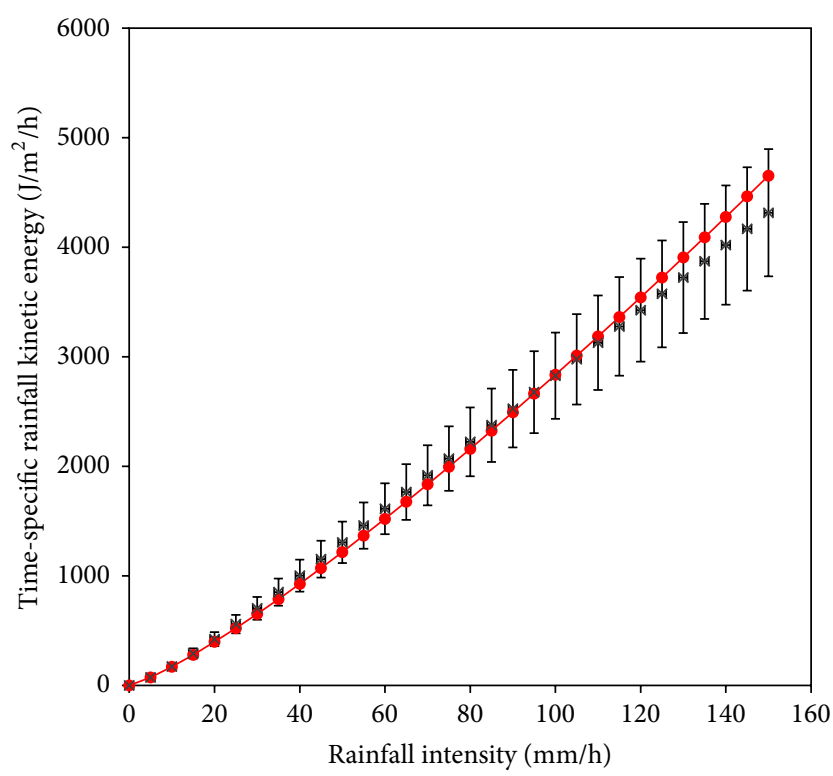

$\times$ Mean energy by exponential functions $\rightarrow a=10.3, b=11 / 9$

(a)

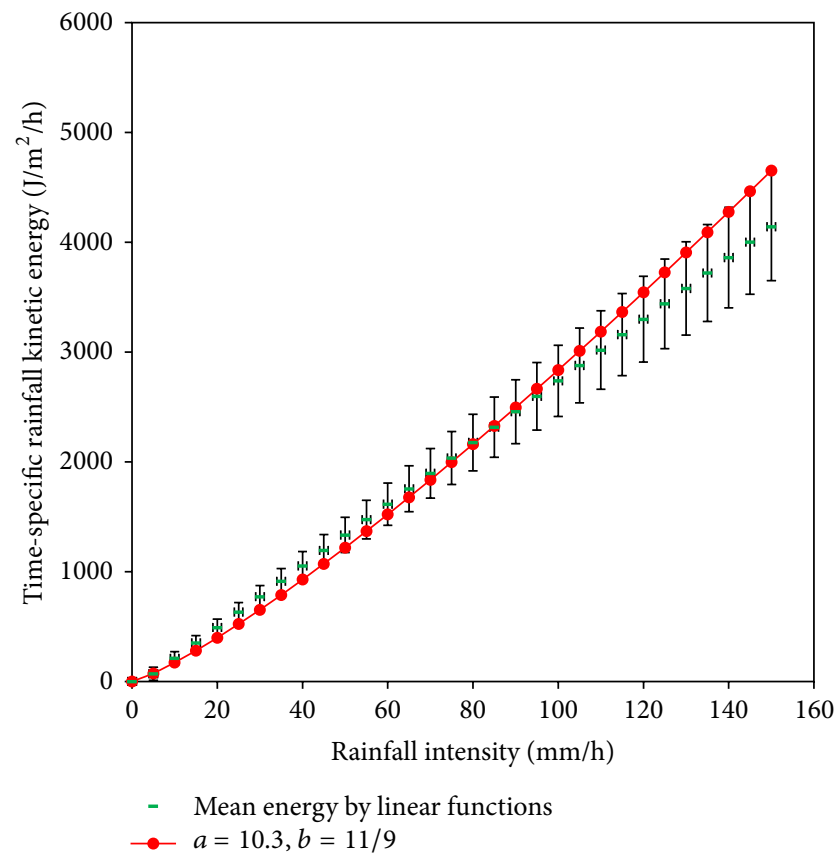

(c)

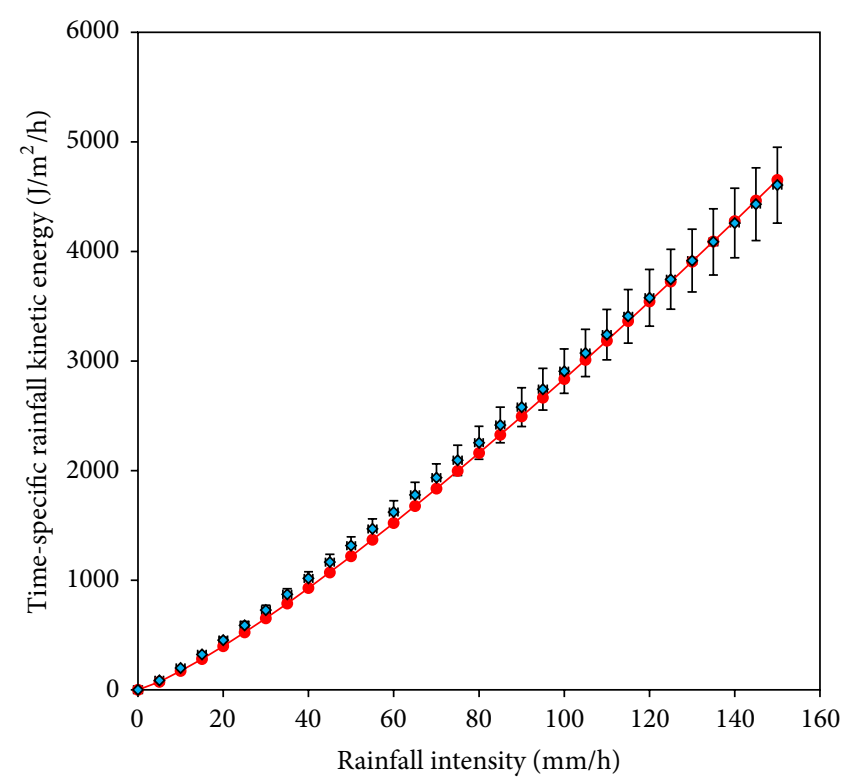

$\diamond \quad$ Mean energy by logarithmic functions $\rightarrow a=10.3, b=11 / 9$

(b)

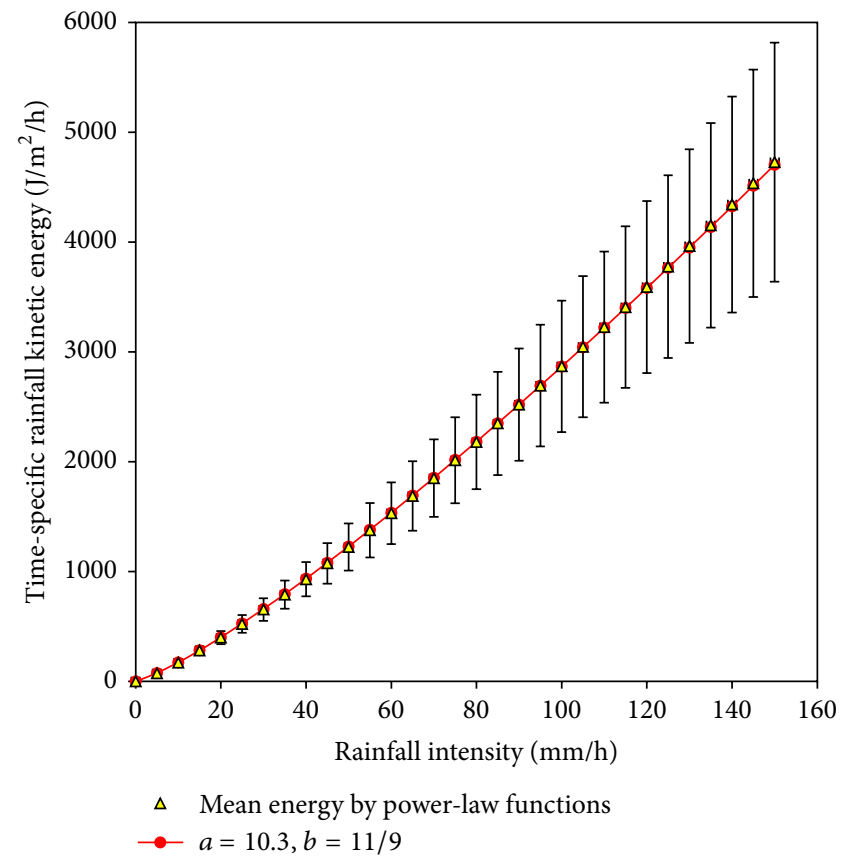

(d)

FIGURE 2: Comparisons of time-specific rainfall kinetic energies calculated by the ideal power law and the exponential functions (a), the logarithmic functions (b), the linear functions (c), and the power-law functions (d).

greater rainfall energy after $I>100 \mathrm{~mm} / \mathrm{h}$ as the exponential function converges to the limited value in higher rainfall intensity $[3,25]$.

Comparison between the ideal equation and 8 logarithmic functions $[3,13,28,34-37]$ is presented in Figure 2(b). The average energy by logarithmic functions was relatively greater than that of the ideal power law; however, the relative difference was minor.

In case of linear functions with the lowest utilization as an equation of rainfall kinetic energy, the average energy by the linear functions $[24,28,38-40]$ became smaller than that of the ideal equation at $I>90 \mathrm{~mm} / \mathrm{h}$, and the relative difference 


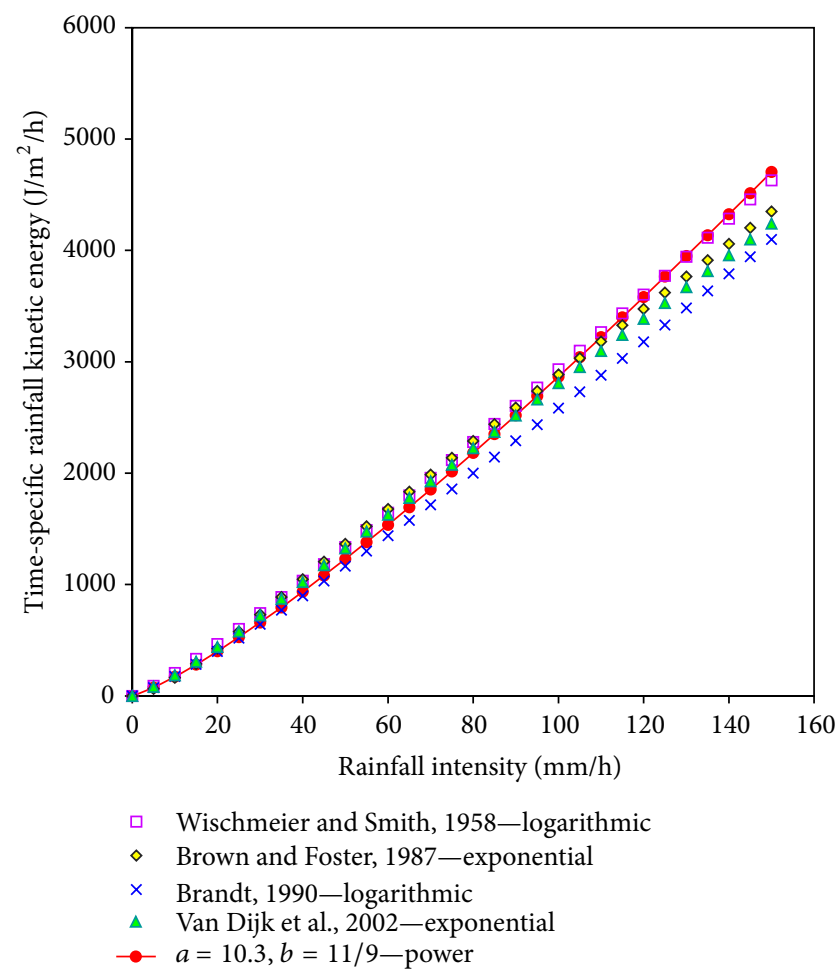

FIGURE 3: Comparison between time-specific kinetic energies calculated by empirical equations used in soil erosion models and timespecific kinetic energy simulated by universal power law according to rainfall intensity.

was largest compared to other functions at the maximum rainfall intensity $(150 \mathrm{~mm} / \mathrm{h})$ (Figure $2(\mathrm{c})$ ).

The rainfall energy simulated by the ideal power law and the average rainfall energy calculated from power laws $[26,28,29,33,41,42]$ showed the greatest deviation of rainfall kinetic energy as shown in Figure 2(d). The average energy calculated by 14 power laws excluding the maximum and minimum kinetic energy equations shown in Table 1 is approximated to the values from the ideal power law. The mean exponent and coefficient deduced from existing power laws were $1.221 \pm 0.068$ and $10.33 \pm 2.16$, respectively, which coincide approximately with the exponent $11 / 9$ and coefficient 10.3 of the ideal power law indicating universal power law.

To utilize the universal power law as an erosivity factor of soil erosion models, it is necessary to conduct a comparative review throughout various rainfall kinetic energy equations used in existing soil erosion models. USLE [13] and EUROSEM [15] used logarithmic functions presented by Wischmeier and Smith [13] and Brandt [19], respectively, and RUSLE [14] and SEMMA [16] used exponential functions developed by Brown and Foster [17] and Van Dijk et al. [20], respectively. Comparison of results simulated from these equations and ideal power law is shown in Figure 3. The simulation results showed that universal power law appears closer to logarithmic function of Wischmeier and Smith [13]. With $I>100 \mathrm{~mm} / \mathrm{h}$, its calculation was found to be greater than other equations. However, the relative difference

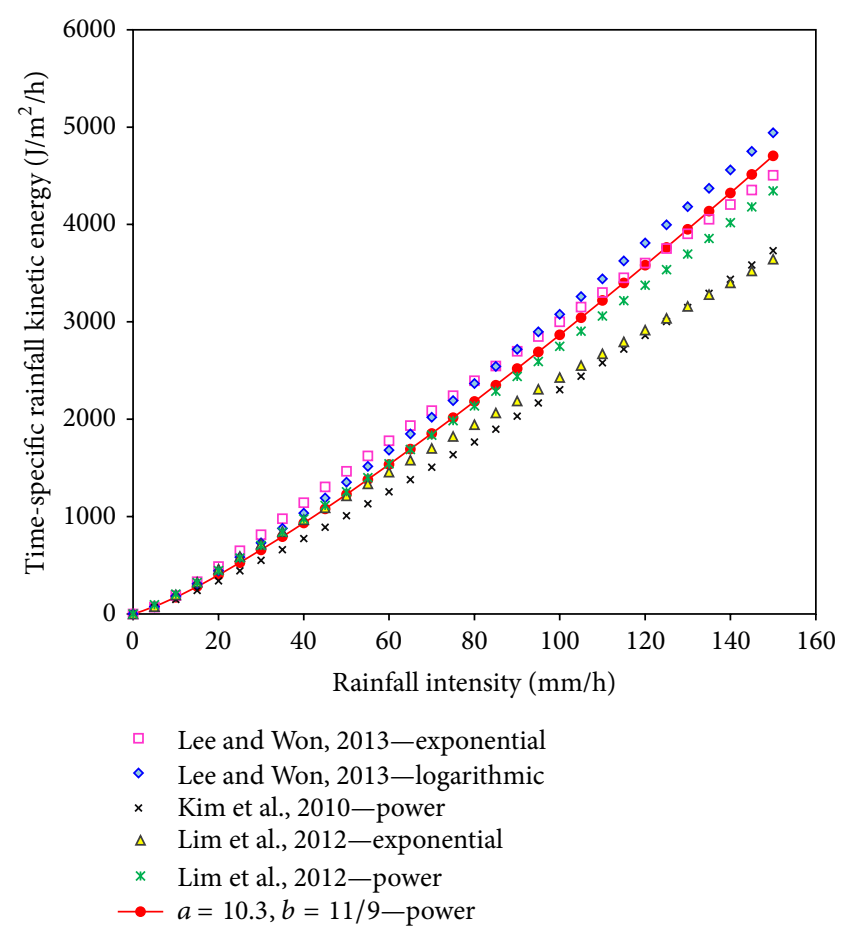

FIgURE 4: Comparison of time-specific kinetic energies between empirical equations presented in South Korea and universal power law.

with these rainfall energy equations showed reasonable value (4.8\%).

The logarithmic, exponential, and power-law functions of the rainfall kinetic energies calculated by continuous DSD measurement data were presented by Kim et al. [42], Lim et al. [33], and Lee and Won [34] in South Korea's representative sites. The rainfall kinetic energies simulated from those equations and universal power law are shown in Figure 4. The results simulated from power law by Lim et al. [33] and exponential and logarithmic functions by Lee and Won [34] showed relatively small difference as compared with the values calculated by universal power law.

Comparison of the average rainfall kinetic energies between various empirical equations and the universal equation was conducted to evaluate whether the universal power law can be used as a representative power law of erosivity factor on soil erosion. The relative difference between the rainfall kinetic energies was calculated in range of $20 \mathrm{~mm} / \mathrm{h}$ $\leq I<160 \mathrm{~mm} / \mathrm{h}$ (Table 2). The relative difference was most significant in case of a linear function at $I=20 \mathrm{~mm} / \mathrm{h}$ while $I>100 \mathrm{~mm} / \mathrm{h}$; the energy of universal power law was found to be relatively greater. Power law showed the smallest relative difference which had the average relative difference of $0.06 \%$. Moreover, exponential function used frequently in soil erosion models had small average relative difference $(0.32 \%)$. Many studies confirmed that there is the maximum value of rainfall kinetic energy and determined that the exponential function with upper limit better describes the relationship between rainfall kinetic energy and rainfall intensity as compared to logarithmic, linear, and power-law 
TABLE 2: Relative differences in kinetic energy between universal power law and average kinetic energies evaluated by empirical equations.

\begin{tabular}{lcccc}
\hline $\begin{array}{l}\text { Rainfall intensity } \\
(\mathrm{mm} / \mathrm{h})\end{array}$ & $\begin{array}{c}\text { Relative difference with } \\
\text { exponential function } \\
(\%)\end{array}$ & $\begin{array}{c}\text { Relative difference with } \\
\text { logarithmic function } \\
(\%)\end{array}$ & $\begin{array}{c}\text { Relative difference } \\
\text { with linear function } \\
(\%)\end{array}$ & $\begin{array}{c}\text { Relative difference } \\
\text { with power law } \\
(\%)\end{array}$ \\
\hline 20 & -5.40 & -12.96 & -22.61 & 0.85 \\
40 & -7.18 & -8.69 & -12.59 & 0.58 \\
60 & -5.09 & -5.67 & -5.17 & 0.33 \\
80 & -1.93 & -3.34 & 0.27 & -0.11 \\
100 & 1.32 & -1.46 & 4.48 & -0.09 \\
120 & 4.33 & 0.13 & 7.88 & -0.27 \\
140 & 7.03 & 1.49 & 10.72 & -0.43 \\
160 & 9.44 & 2.69 & 13.13 & -0.58 \\
Ave. & 0.32 & -3.48 & -0.49 & 0.06 \\
S.D. & 5.79 & 5.02 & 11.53 & 0.47 \\
\hline
\end{tabular}

functions with no upper limit [3, 17, 21-25]. In addition, Van Dijk et al. [20] proposed a general exponential equation based on comprehensive measurement data by reviewing literature. Actually, the kinetic energy of freefalling raindrops has the upper limit due to limited maximum size of raindrop in the order of $6-8 \mathrm{~mm}[2,10,52]$. However, power law simulated excessively in high rainfall intensity may be more useful than exponential function in evaluating soil erosion because sediment transport capacity of running water increases with the rainfall kinetic energy. Interrill erosion model linked to power-law relationship with rainfall intensity has been adopted that the exponent of power law was approximated by $\geq 2$ [54-56]. Therefore, the universal power law that used ideal assumption would take great advantages in utilization as erosivity factor to determine a quantitative assessment of soil erosion.

\section{Conclusion}

The empirical rainfall kinetic energy equations determined by the characteristics of the DSD have a variety of functional forms. In case of power laws, especially, the relative deviations of calculated energies depend on the exponents and coefficients of power laws. This study proposed a representative power law. The time-specific rainfall kinetic energy equation based on the power theory was derived through the ideal assumption that the drop-size is uniformly distributed under the constant rainfall intensity. The exponent of ideal power law was $11 / 9$, and the coefficient was 10.3 which obtained from the relationship between exponents and coefficients of existing empirical power laws. The rainfall energy calculated by ideal equation was compared with results simulated by existing exponential, logarithmic, linear, and power-law functions. The logarithmic function showed the smallest deviation as compared to the ideal power law. The ideal equation in $I>100 \mathrm{~mm} / \mathrm{h}$ overestimated in comparison with exponential and linear functions. The mean rainfall kinetic energy calculated from empirical power laws corresponded approximately with the results of ideal power law. This supports that the ideal equation can be a universal form of the power law. The universal power law in comparison with rainfall kinetic energy equations used in typical soil erosion models showed that the relative difference was within $5 \%$, and there was no significant deviation in relationship with equations of rainfall kinetic energy presented by DSD measurement. It was also confirmed that the relative differences in the average rainfall kinetic energy between various empirical equations and universal equation of rainfall power law were not significant. These results prove that the universal power law can represent the existing empirical power laws. There was a trend that the kinetic energy by universal power law had relatively overestimated as compared to other empirical equations in $I>100 \mathrm{~mm} / \mathrm{h}$. However, this result supports the conclusion that it can be more useful in the development of soil erosion models due to significant increase in sediment yield by increasing transport capacity of surface runoff in the high rainfall intensity $(I>100 \mathrm{~mm} / \mathrm{h})$.

\section{Conflict of Interests}

The authors declare that there is no conflict of interests regarding the publication of this paper.

\section{Acknowledgment}

This research was supported by Basic Science Research Program through the National Research Foundation of Korea (NRF) funded by the Ministry of Education, Science and Technology (no. 2013R1A1A3011962).

\section{References}

[1] M. J. Hall, "Use of the stain method in determining the drop size distribution of coarse liquid sprays," Transactions of the American Society of Agricultural Engineers, vol. 13, pp. 33-37, 1970.

[2] J. O. Laws and D. A. Parsons, "The relation of raindrop size to intensity," Transactions of the American Geophysical Union, vol. 26, pp. 452-460, 1943.

[3] P. I. A. Kinnell, "Rainfall intensity-kinetic energy relationships for soil loss prediction," Soil Science Society of America Journal, vol. 45, no. 1, pp. 153-155, 1981. 
[4] G. F. McIsaac, "Apparent geographic and atmospheric influences on raindrop sizes and rainfall kinetic energy," Journal of Soil \& Water Conservation, vol. 45, no. 6, pp. 663-666, 1990.

[5] T.-I. Wang, K. B. Earnshaw, and R. S. Lawrence, "Path-averaged measurements of rain rate and raindrop size distribution using a fast-response optical sensor," Journal of Applied Meteorology, vol. 18 , no. 5, pp. 654-660, 1979.

[6] A. J. Illingworth and C. J. Stevens, "An optical disdrometer for the measurement of raindrop size spectra in windy conditions," Journal of Atmospheric and Oceanic Technology, vol. 4, no. 3, pp. 411-421, 1987.

[7] C. Salles and J. Poesen, "Performance of an optical spectro pluviometer in measuring basic rain erosivity characteristics," Journal of Hydrology, vol. 218, no. 3-4, pp. 142-156, 1999.

[8] J. O. Laws, "Measurements of the fall-velocity of water-drops and raindrops," Eos, Transactions American Geophysical Union, vol. 22, pp. 709-721, 1941.

[9] R. Gunn and G. D. Kinzer, "The terminal velocity of fall for water droplets in stagnant air," Journal of Meteorology, vol. 6, no. 4, pp. 243-248, 1949.

[10] K. V. Beard, "Terminal velocity and shape of cloud and precipitation drops aloft," Journal of the Atmospheric Sciences, vol. 33, no. 5, pp. 851-864, 1976.

[11] N. W. Hudson, "An intorduction to the mechanics of soil erosion under conditions of sub-tropical rainfall," Transactions of the Rhodesia Scientific Association, vol. 49, pp. 15-25, 1961.

[12] A. W. Jayawardena and R. B. Rezaur, "Measuring drop size distribution and kinetic energy of rainfall using a force transducer," Hydrological Processes, vol. 14, no. 1, pp. 37-49, 2000.

[13] W. H. Wischmeier and D. D. Smith, "Rainfall energy and its relationship to soil loss," Transactions of the American Geophysical Union, vol. 39, no. 2, pp. 285-291, 1958.

[14] K. G. Renard, G. R. Foster, G. A. Weesies, D. K. McCool, and D. C. Yoder, "Predicting soil erosion by water: a guide to conservation planning with the Revised Universal Soil Loss Epuation (RUSLE)," in US Department of Agriculture Handbook 703, US Department of Agriculture, Agricultural Search Service, Washington, DC, USA, 1997.

[15] R. P. C. Morgan, J. N. Quinton, R. E. Smith et al., “The European soil erosion model (EUROSEM): a dynamic approach for predicting sediment transport from fields and small catchments," Earth Surface Processes and Landforms, vol. 23, no. 6, pp. 527$544,1998$.

[16] S. D. Park, K. S. Lee, and S. S. Shin, "A statistical soil erosion model for burnt mountain areas in Korea-RUSLE approach," Journal of Hydrologic Engineering, vol. 17, no. 2, pp. 292-304, 2012.

[17] L. C. Brown and G. R. Foster, "Storm erosivity using idealized intensity distributions," Transactions of the American Society of Agricultural Engineers, vol. 30, no. 2, pp. 379-386, 1987.

[18] J. S. Marshall and W. M. Palmer, "The distribution of raindrop with size," Journal of Meteorology, vol. 5, pp. 165-166, 1948.

[19] C. J. Brandt, “The size distribution of throughfall drops under vegetation canopies," CATENA, vol. 16, no. 4-5, pp. 507-524, 1989.

[20] A. I. J. M. Van Dijk, L. A. Bruijnzeel, and C. J. Rosewell, "Rainfall intensity-kinetic energy relationships: a critical literature appraisal," Journal of Hydrology, vol. 261, no. 1-4, pp. 1-23, 2002.

[21] N. W. Hudson, "Raindrop size distribution in high intensity storms," Rhodesian Journal of Agricultural Research, vol. 1, pp. 6-11, 1963.
[22] P. C. Baruah, An investigation of drop size distribution of rainfall in Thailand [M.S. thesis], Asian Institute of Technology, Bangkok, Thailand, 1973.

[23] C. E. Carter, J. D. Greer, H. J. Braud, and J. M. Floyd, "Raindrop characteristics in south central United States," Transactions of the American Society of Agricultural Engineers, vol. 17, no. 6, pp. 1033-1037, 1974.

[24] C. J. Rosewell, "Rainfall kinetic energy in eastern Australia," Journal of Climate \& Applied Meteorology, vol. 25, no. 11, pp. 1695-1701, 1986.

[25] W. H. Wischmeier and D. D. Smith, "Predicting rainfall erosion losses," in Agriculture Handbook No. 537, U.S. Department of Agriculture, Washington, DC, USA, 1978.

[26] J. A. Smith and R. D. de Veaux, "The temporal and spatial variability of rainfall power," Environmetrics, vol. 3, no. 1, pp. 29-53, 1992.

[27] C. Salles, J. Poesen, and D. Sempere-Torres, "Kinetic energy of rain and its functional relationship with intensity," Journal of Hydrology, vol. 257, no. 1-4, pp. 256-270, 2002.

[28] R. L. Fornis, H. R. Vermeulen, and J. D. Nieuwenhuis, "Kinetic energy-rainfall intensity relationship for Central Cebu, Philippines for soil erosion studies," Journal of Hydrology, vol. 300, no. 1-4, pp. 20-32, 2005.

[29] R. Uijlenhoet and J. N. M. Stricker, "A consistent rainfall parameterization based on the exponential raindrop size distribution," Journal of Hydrology, vol. 218, no. 3-4, pp. 101-127, 1999.

[30] D. C. Blanchard, "Raindrop size-distribution in Hawaiian rains," Journal of Meteorology, vol. 10, no. 6, pp. 457-473, 1953.

[31] M. Azevedo Coutinho and P. Pereira Tomás, "Characterization of raindrop size distributions at the Vale Formoso Experimental Erosion Center," CATENA, vol. 25, no. 1-4, pp. 187-197, 1995.

[32] A. W. Jayawardena and R. B. Rezaur, "Drop size distribution and kinetic energy load of rainstorms in Hong Kong," Hydrological Processes, vol. 14, no. 6, pp. 1069-1082, 2000.

[33] Y. S. Lim, J. W. Kim, J. K. Kim, and B. I. Park, "Evaluation of kinetic energy of raindrops at Daejeon city using laseroptical disdrometer," Journal of the Korean Geomorphological Association, vol. 19, no. 2, pp. 133-143, 2012.

[34] J. S. Lee and J. Y. Won, "Analysis of the characteristic of monthly rainfall erosivity in Korea with derivation of rainfall energy equation," Journal of Korean Society of Hazard Mitigation, vol. 13, no. 3, pp. 177-184, 2013.

[35] K. Onaga, K. Shirai, and A. Yoshinaga, "Rainfall erosion and how to control its effects on farmland in Okinawa," in Land Conservation for Future Generation, S. Rimwanich, Ed., pp. 627639, Department of Land Development, Bangkok, Thailand, 1988.

[36] C. Zanchi and D. Torri, "Evaluation of rainfall energy in central Italy, in Assessment of Erosion, M. de Boodt and D. Gabriels, Eds., pp. 133-142, Wiley, Toronto, Canada, 1980.

[37] C. J. Brandt, "Simulation of the size distribution and erosivity of raindrops and throughfall drops," Earth Surface Processes \& Landforms, vol. 15, no. 8, pp. 687-698, 1990.

[38] N. W. Hudson, The influence of rainfall mechanics on soil erosion [MSc. thesis], Cape Town University, Cape Town, South Africa, 1965.

[39] D. Sempere-Torres, C. Salles, J. D. Creutin, and G. Delrieu, "Quantification of soil detachment by raindrop impact: performance of classical formulae of kinetic energy in Mediterranean storms. Erosion and sediment transport monitoring programs in river basin," IASH Publications, vol. 210, pp. 115-124, 1992. 
[40] A. Usón and M. C. Ramos, "An improved rainfall erosivity index obtained from experimental interrill soil losses in soils with a mediterranean climate," CATENA, vol. 43, no. 4, pp. 293-305, 2001.

[41] M. Steiner and J. A. Smith, "Reflectivity, rain rate, and kinetic energy flux relationships based on raindrop spectra," Journal of Applied Meteorology, vol. 39, no. 11, pp. 1923-1940, 2000.

[42] J. K. Kim, D. Y. Yang, and M. S. Kim, "Evaluating physical characteristics of raindrop in Anseong Gyeonggi province," Journal of the Korean Geomorphological Association, vol. 17, no. 1, pp. 49-57, 2010.

[43] P. I. A. Kinnell, "The problem of assessing the erosive power of rainfall from meteorological observations," Soil Science Society of America, vol. 37, no. 4, pp. 617-621, 1973.

[44] D. S. Torres, J. M. Porrà, and J. D. Creutin, "A general formulation for raindrop size distribution," Journal of Applied Meteorology, vol. 33, no. 12, pp. 1494-1502, 1994.

[45] L. V. Madden, L. L. Wilson, and N. Ntahimpera, "Calibration and evaluation of an electronic sensor for rainfall kinetic energy," Phytopathology, vol. 88, no. 9, pp. 950-959, 1998.

[46] D. Sempere-Torres, J. M. Porrà, and J.-D. Creutin, "Experimental evidence of a general description for raindrop size distribution properties," Journal of Geophysical Research D: Atmospheres, vol. 103, no. 2, pp. 1785-1797, 1998.

[47] A. C. Best, “The size distribution of raindrops," Quarterly Journal of The Royal Meteorological Society, vol. 76, pp. 16-36, 1950.

[48] C. W. Ulbrich, "Natural variations in the analytical form of the raindrop size distribution," Journal of Climate \& Applied Meteorology, vol. 22, no. 10, pp. 1764-1775, 1983.

[49] G. Feingold and Z. Levin, "The lognormal fit to raindrop spectra from frontal convective clouds in Israel," Journal of Climate \& Applied Meteorology, vol. 25, no. 10, pp. 1346-1363, 1986.

[50] D. Atlas and C. W. Ulbrich, "Path- and area-integrated rainfall measurement by microwave attenuation in the $1-3 \mathrm{~cm}$ band," Journal of Applied Meteorology, vol. 16, pp. 1322-1331, 1977.

[51] C. Salles, D. Sempere-Torres, and J. D. Creutin, "Characterisation of raindrop size distribution in Mediterranean climate: analysis of the variations on the Z-R relationship," in Proceedings of the 29th Conference on Rada Meteorology, pp. 671-673, AMS, Montreal, Canada, July 1999.

[52] J. Joss and A. Waldvogel, "Raindrop size distribution and sampling size errors," Journal of the Atmospheric Sciences, vol. 26, no. 3, pp. 566-569, 1969.

[53] G. Zhou, X. Wei, and J. Yan, "Impacts of eucalyptus (Eucalyptus exserta) plantation on sediment yield in Guangdong Province, Southern Chin-a kinetic energy approach," CATENA, vol. 49, no. 3, pp. 231-251, 2002.

[54] L. D. Meyer, "How rain intensity affects rill erosion," Transaction American Society of Agricultural Engineers, vol. 24, no. 6, pp. 1472-1475, 1981.

[55] C. C. Truman and J. M. Bradford, "Relationships between rainfall intensity and the interrill soil loss-slope steepness ratio as affected by antecedent water content," Soil Science, vol. 156, no. 6, pp. 405-413, 1993.

[56] A. J. Parsons and P. M. Stone, "Effects of intra-storm variations in rainfall intensity on interrill runoff and erosion," CATENA, vol. 67 , no. 1, pp. 68-78, 2006. 

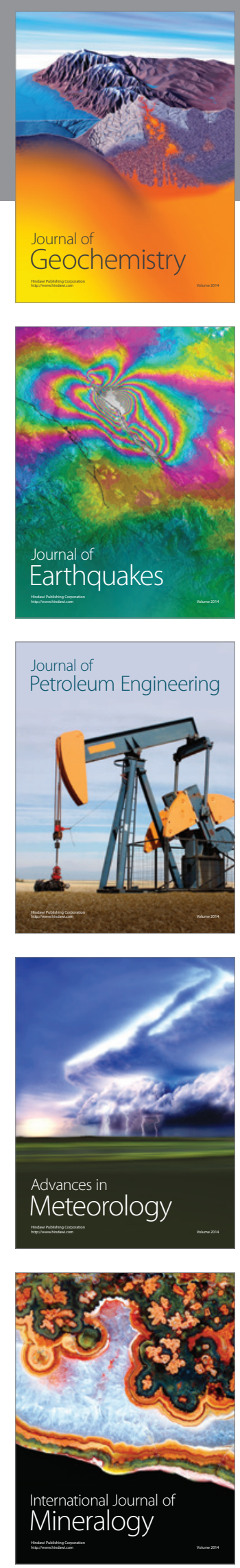
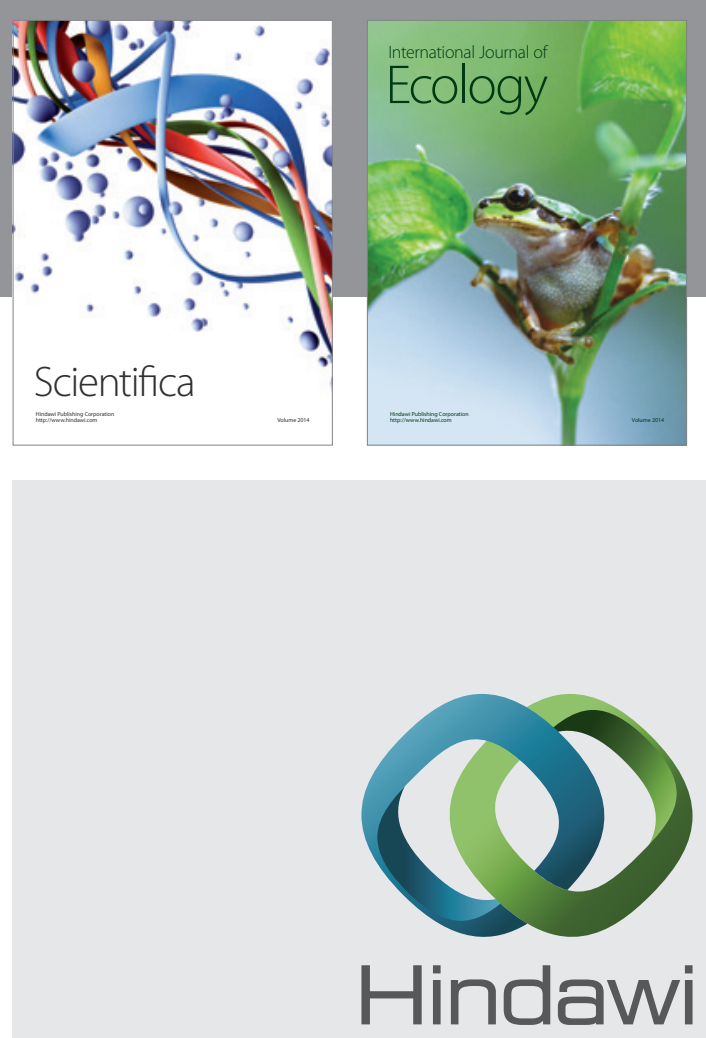

Submit your manuscripts at

http://www.hindawi.com
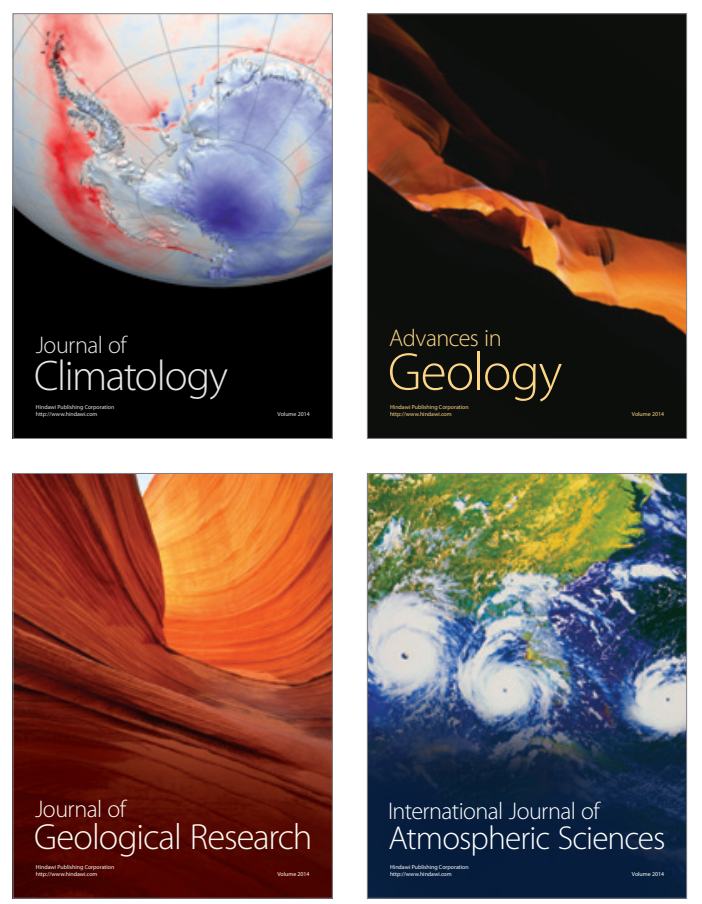

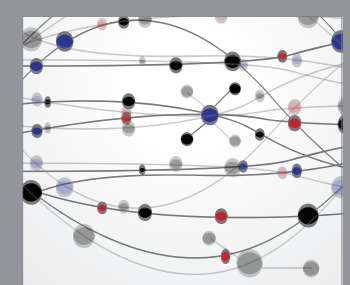

The Scientific

\section{World Journal}
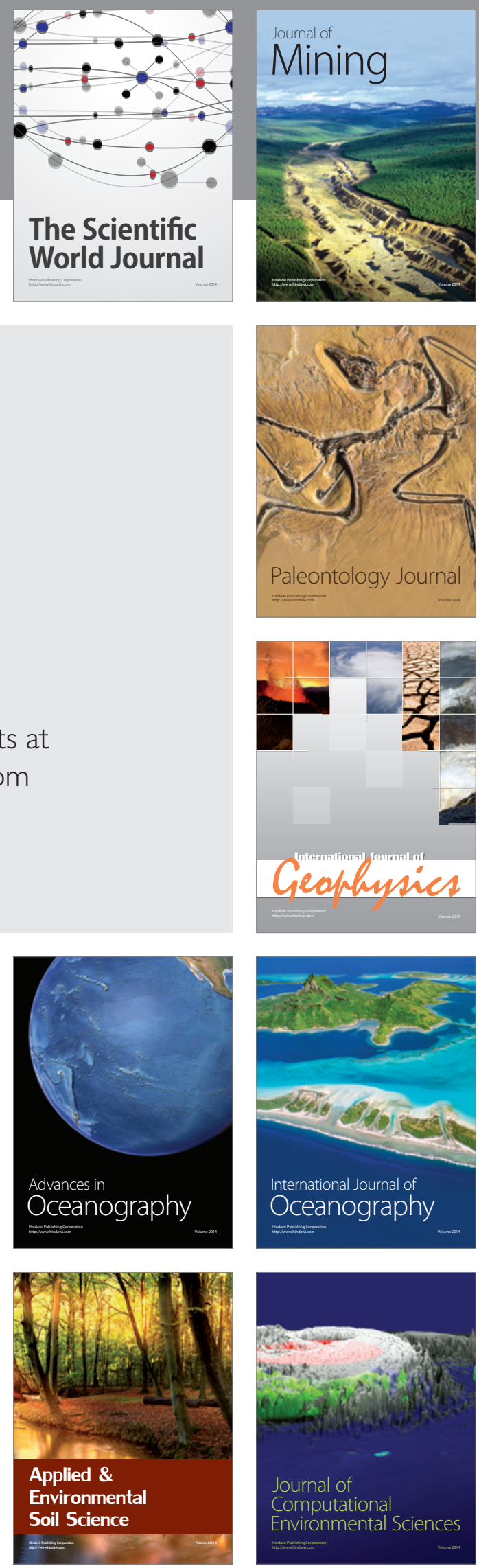